\title{
In vitro evaluation of plant essential oils against Alternaria alternata causing fruit rot of grapes
}

\author{
Awais Sajid ${ }^{1}$, Gulshan Irshad ${ }^{1}$, Farah Naz ${ }^{1}$, Salman Ghuffar ${ }^{1 *}$, Imran Hassan ${ }^{2}$, Nasir Mahmood ${ }^{1}$, Komal Rani ${ }^{1}$, \\ Muhammad Faizan Manzoor ${ }^{1}$, Ali Meesam ${ }^{1}$, Abdul Mannan Hamzah ${ }^{3}$, Muhammad Zunair Karamt ${ }^{1}$ \\ ${ }^{1}$ Department of Plant Pathology, PMAS-Arid Agriculture University, Rawalpindi, Pakistan \\ ${ }^{2}$ Department of Horticulture, PMAS-Arid Agriculture University, Rawalpindi, Pakistan \\ ${ }^{3}$ Department of Entomology, PMAS-Arid Agriculture University, Rawalpindi, Pakistan
}

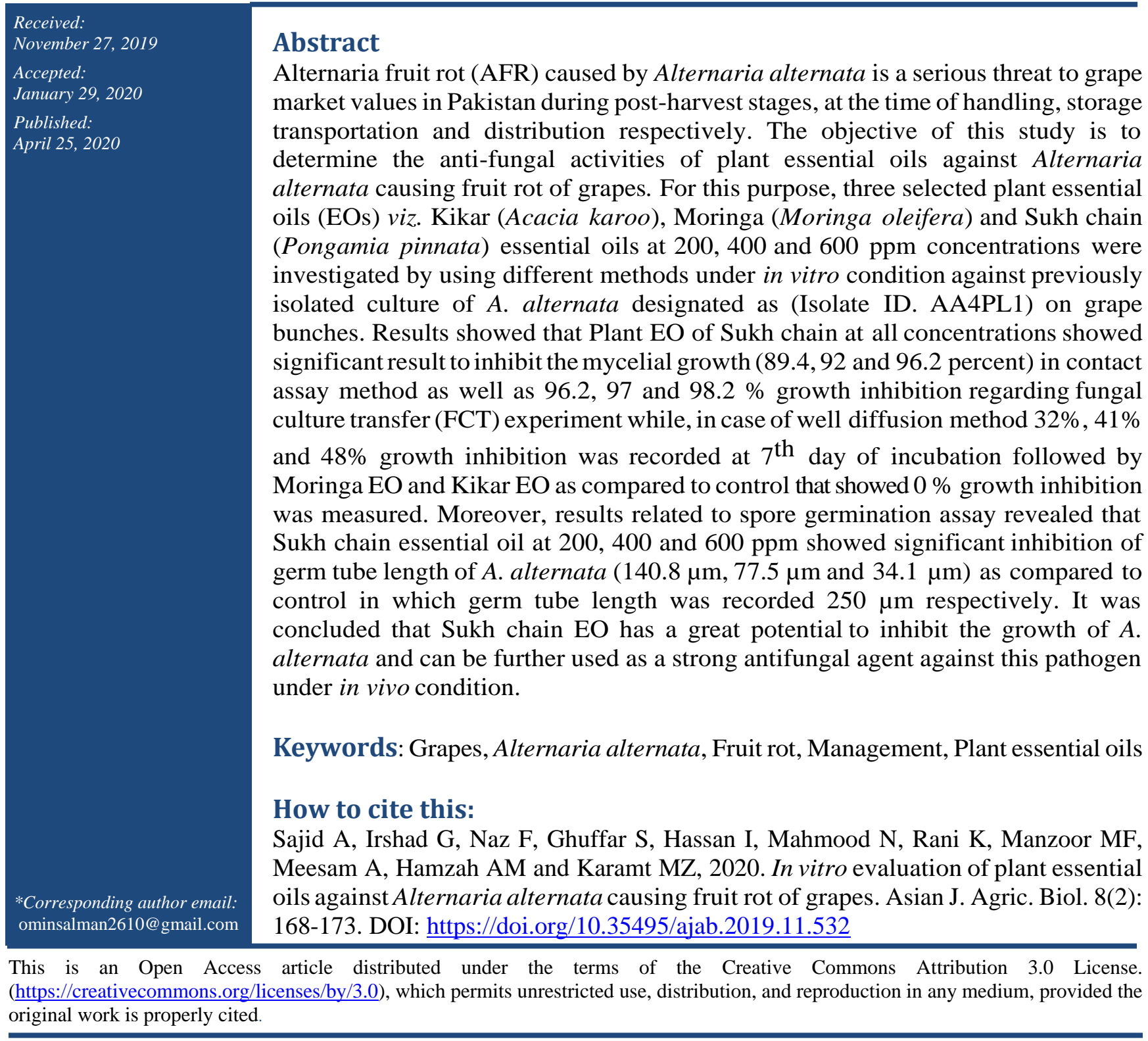




\section{Introduction}

Grapes (Vitis vinifera L.) are widely cultivated, economically important and highly nutritious fruit throughout the world (Ali et al., 2010). Grapes are also familiar as a "Queen of fruits" due to good source of multi-vitamins such as A \& $\mathrm{C}$ as well as it contains a lot of bioactive compounds such as anthocyanins, carotenoids and some important antioxidants which has an important role to enhance the immune system (Rathi and Rajput, 2014). In Pakistan, grapes are mostly cultivated for fresh consumptions covered area of about 14 thousand Hectare with an annual production of 57 thousand tons. Besides its nutritional and medicinal values grape is one of the perishable fruit, having limited shelf life up to 3 to 4 days at ambient temperature. The maximum perishability of this fruit during handling, storage and marketing is due to susceptibility toward numerous post-harvest fungal diseases like Mucor rot (MR) (Ghuffar et al., 2018a), Botrytis bunch rot (Javed et al., 2017) Penicillium rot (PR) (Ghuffar et al., 2018b) and especially Alternaria fruit rot (AFR) associated with Alternaria alternata is responsible for weight loss, colour changes, softening of grape berries, increases the market losses up to $50 \%$ and eventually has badly impact on economy (Valero et al., 2006). In addition, Alternaria genus produce mycotoxin such as tenuazonic acid (TA), alternariol monomethyl ether (AME) alternariol $(\mathrm{AOH})$ these mycotoxins are carcinogenic for human health and physically deteriorate the whole bunches of grapes (Logrieco et al., 2009). For the control of Alternaria rot, Farmers spray synthetic fungicides on small fruits. However, these fungicides have some residual effect on berries skin which may lead to development of resistant fungi, oncogenic risk, handling hazards, and threats to the environment (Daferera et al., 2003). Therefore, many restrictions regarding application of chemical fungicides on small fruits are banned in many countries of the world (Arroyo et al., 2007; Tzortzakis, 2007). Nowadays, researchers have keen interest to provide some safer alternatives which have non-hazardous effects on environment as a replacement of chemical fungicides for farmers. They successfully found some biological methods, such as use of plant essential oils (EOs) are an exciting alternative. These Plant essential oils are volatile compounds, broad spectrum, anti- fungal activity, eco-friendly and more acceptable to the public (Wang et al., 2007). Keeping in all the view, the present study was conducted to find out the efficacy of different plant essential oils against Alternaria alternata causing fruit rot of grapes under in vitro condition.

\section{Material and Methods}

\section{Collection of pathogenic fungal culture}

The culture of Alternaria alternata, previously isolated from infected grape bunches of Perlette cv. designated as isolate AA4PL1 was from mycology lab, Department of Plant Pathology, PMAS-Arid Agriculture University Rawalpindi (AAUR) with Genebank submission ID. Alt 05, Accession No. MF785102 (Ghuffar et al., 2018c) respectively. Stock culture of fungal isolate was preserved at 4 ${ }^{\circ} \mathrm{C}$ in glass vials by using silica gel technique. Preserved fungal culture of Alternaria alternata was re-cultured by transferring beads onto freshly prepared Potato Dextrose Agar (PDA) in Petri dishes and incubated for 7 days at $25{ }^{\circ} \mathrm{C}$. After revival, culture was purified and placed in incubator for seven days at $25^{\circ} \mathrm{C}$ using PDA media and finally used for further management trials under in vitro conditions.

In vitro screening of Aternaria alteranta by using plant essential oils (EOs) Extraction of plant essential oils (EOs) through Soxhlet's apparatus Matured Leaves of sukh chain (Pongamia pinnata), moringa (Moringa oleifera) and small branches of kikar (Acacia karoo) were taken from Dajal Rajanpur and horticultural research station of PMAS- UAAR. These botanical materials were first dried under shadow, ground well in grinder machine and subjected for extraction process through Soxhlet's apparatus followed by (Sahin et al., 2003). Finally, extracted Plant essential oils (EOs) was in a clean glass vials and stored in refrigerator at $4^{\circ} \mathrm{C}$ until further tested

\section{In vitro contact assay}

To find out the efficacy of different plant essential oils on mycelial growth of Alternaria alternata poisoned food technique was used. For this purpose, $50 \mathrm{ml}$ of prepared Potato Dextrose Agar media were kept in $100 \mathrm{~mL}$ conical flasks, sterilized for $20 \mathrm{~min}$ and kept under sterilized hood to cool up to $60^{\circ} \mathrm{C}$ then plant EOs were added to each flasks and shacked gently to prepare PDA media 
containing 200, 400 and 600 ppm of concentrations. $9 \mathrm{~cm}$ Petri plates were poured with PDA containing known concentrations of plant EOs. $5 \mathrm{~mm}$ plug of 7 days old culture of A. alternata were kept in the center of each Petri plate whereas, in control sets PDA free of any essential oils were used. After that Petri dishes were incubated at $\pm 25{ }^{\circ} \mathrm{C}$ for 7 days and finally, mycelial inhibition concentration percentage (MIC) was recorded by using the following formula (Dauria et al., 2005):

$$
\operatorname{MIC} \%=\frac{\mathrm{c}-\mathrm{t}}{\mathrm{c}} \times 100
$$

where $\mathrm{c}$ means (diameter of control), $\mathrm{t}$ (diameter of treatment). The Analysis was replicated 3 times.

\section{Fungal culture transfer Experiment}

Transfer experiment was done to check the viability of the fungal culture which utilized in contact assay. For this purpose, from seven days old contact assay fungal plates, $6 \mathrm{~mm}$ plugs of fungal culture were shifted in a new plate. No essential oils (EOs) were used at this stage, later plates were incubated at \pm 25 ${ }^{\circ} \mathrm{C}$ for 7 days. Mycelial growth of the pathogen was measured by using formula described earlier. The data was recorded after $7^{\text {th }}$ day of incubation with three replications (Feng and Zheng, 2007).

\section{Well diffusion technique}

Agar well diffusion is reliable technique used to screen out the anti-fungal activity of different plants essential oils. According to this method, two wells were made aseptically with a sterile cork borer at equidistant from each other and one well was filled by Alternaria alternata inoculum $\left(10^{7}\right.$ spores $\left./ \mathrm{mL}\right)$ while second with plant essential oils at defined concentrations of 200, 400 and $600 \mathrm{ppm}$ respectively. Furthermore, Agar plates were incubated at $\pm 25^{\circ} \mathrm{C}$. The plant (EOs) were diffused in the agar medium which inhibited the growth of the A. alternata. Linear growth inhibition was measured after 7 days and mycelial growth of pathogen was calculated by using the formula as same as previously described in vitro contact assay experiment.

\section{Spore germination assay}

The experiment was conducted in Potato Dextrose Broth (PDB) to find out the impact of most effective essential oil on germ tube length of Alternaria alternata. For this experiment, glass tubes were used having $10 \mathrm{ml}$ space and poured with $5 \mathrm{ml} \mathrm{PDB}$ in each glass tube. After that aliquots (100 ul) having spore suspensions with concentration of $\left(10^{7}\right.$ spores $/ \mathrm{ml}$ ) of A. alternata was added to each tube. Glass tubes were incubated at $\pm 28{ }^{\circ} \mathrm{C}$ for $20 \mathrm{~h}$ on a rotatory shaker at 200 round per minutes (rpm). The germ tube length was observed after 20 hours with the help of microscope. Three Readings were taken for formula followed by (Feng \& Zheng, 2007).

\section{Statistical analysis}

Statistical analysis of all experiments were conducted in triplicate and data were expressed as mean \pm standard deviation after analyzed via CRD two factorial design (statistics $10.0 \mathrm{v}$ ). The statistical significance was set at a confidence level of $\mathrm{p}<$ 0.05 .

\section{Results}

\section{In vitro contact assay}

After the application of three selected plant essential oils under in vitro condition by using contact assay method. Data recorded after 7 days revealed that Sukh chain EO was most effective to inhibit the mycelial fungal growth 89.4, 92 and 96.2 percent at all applied concentrations (200, 400 and $600 \mathrm{ppm}$ ) followed by Moringa EO 58.9, 65.7, $68.3 \%$ while Kikar EO showed least efficacy $46.4 \%, 55.3 \%$ and $59.2 \%$ respectively. Whereas, in control set none of mycelial inhibition $\%$ was recorded as shown as in Figure 1

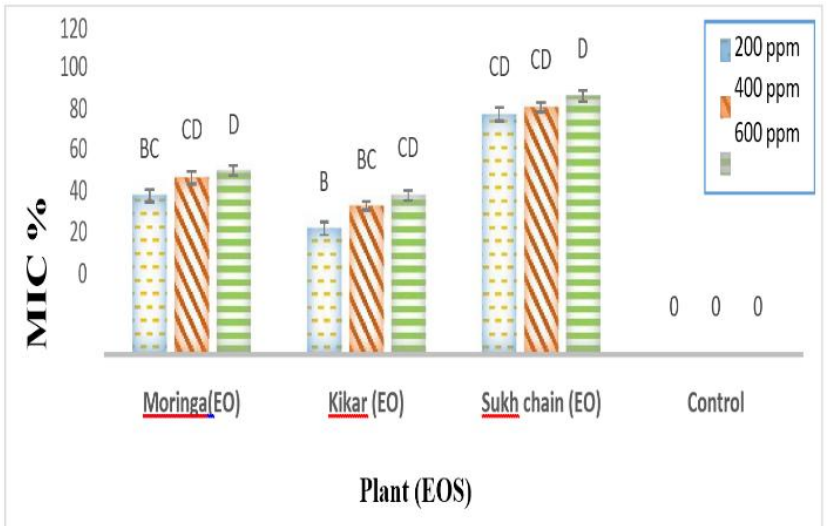

Figure-1: Efficacy of Plant essential oils at different concentrations after 7 days of incubation against Alternaria alternata 


\section{Fungal culture transfer experiment}

A Similar result was found regarding in transfer experiment on $7^{\text {th }}$ day demonstrated that Sukh chain essential oil at concentrations 200, 400 and 600 ppm showed significant result 96.2, 97 and 98.2 percent followed by Moringa oil 62.5,

66.7 and $71.5 \%$ value while Kikar oil showed minimum effectiveness $(52.5,58.2$ and $63.2 \%)$ as compared to control where $0 \%$ growth inhibition

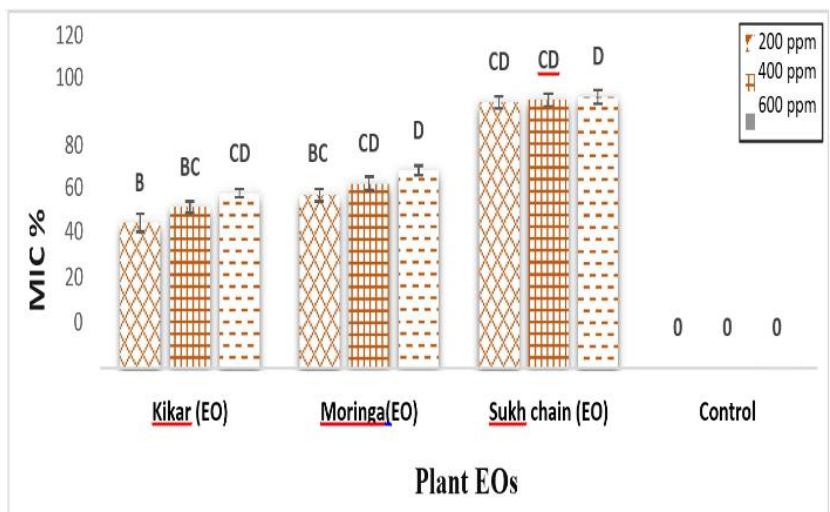

was recorded (Figure 2).

Figure-2: Effectiveness of Plant (EOs) on growth inhibition of Alternaria alternate on $7^{\text {th }}$ day through transfer experiment

\section{Well diffusion method}

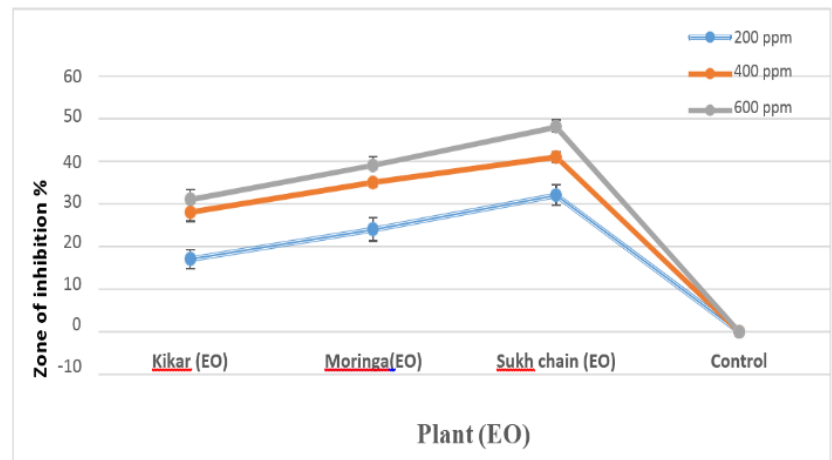

Figure-3: Effect of plant essential oils applied at three (200 ppm, $400 \mathrm{ppm}$ and, $600 \mathrm{ppm})$ concentrations on growth inhibition zone of Alternaria alternata through well diffusion technique

From three selected plant essential oils Sukh chain EO was applied at pre-defined three doses of 200 ppm, $400 \mathrm{ppm}$ and $600 \mathrm{ppm}$ per well through well diffusion technique produce $32 \%, 41 \%$ and $48 \%$ growth inhibition zone percent respectively at $7^{\text {th }}$ day of incubation after adding extract and fungal spore suspension in their respective wells while, Moringa EO showed the inhibition zone of pathogen at $600 \mathrm{ppm}$ and $400 \mathrm{ppm}$ doses after Sukh chain EO by expressing $39 \%$ and $35 \%$ growth inhibition respectively while $200 \mathrm{ppm}$ dose showed $24 \%$ zone of inhibition at $7^{\text {th }}$ day of incubation. In case of Kikar EO expressed growth inhibition of $31 \%$ at dose of $600 \mathrm{ppm}$ while $28 \%$ as well as $17 \%$ at doses of $400 \mathrm{ppm}$ and 200ppm per well in PDA media as compared to control which showed $0 \%$ growth inhibition (Figure 3). Fungal growth was recorded at 7 day of incubation.

\section{Spore germination assay}

After conducting in vitro contact assay and well diffusion experiments to determine the effectiveness of plant essential oils against Alternaria alternata. Sukh chain (EO) showed maximum growth inhibition $\%$ and used for further in spore germination assay experiment.

\section{Length of germ tube}

Sukh chain inhibited the germ tube length of Alternaria alternata on 7 days at concentrations (200, 400 and $600 \mathrm{ppm}$ ) but had some variations in terms of length measurement. At $200 \mathrm{ppm}$ concentration germ tube length was recorded 140.8 $\mu \mathrm{m}$ under microscope observations followed by 77.5 $\mu \mathrm{m}$ length measured at $400 \mathrm{ppm}$ while minimum length of $34.1 \mu \mathrm{m}$ at $600 \mathrm{ppm}$ concentration as compared to control germ tube length was recorded maximum $250 \mu \mathrm{m}$ respectively (Figure 4 ).

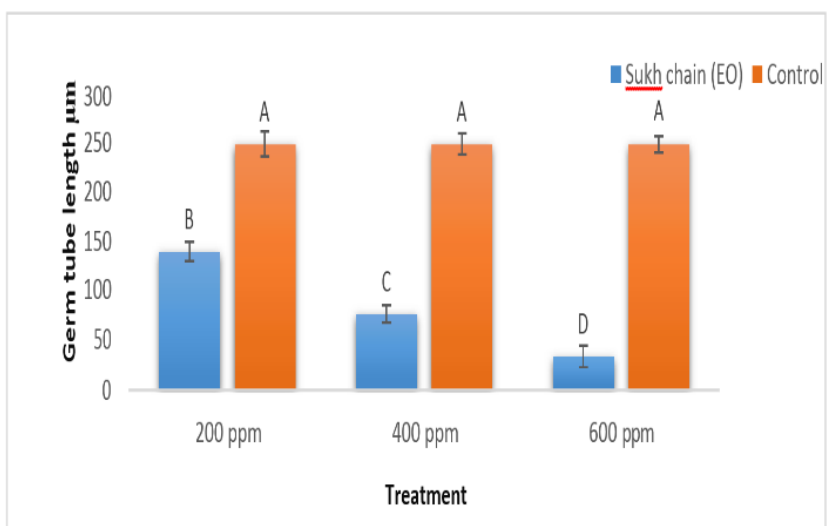

Figure-4: Germ tube length $(\mu \mathrm{m})$ of Alternaria alternata on $7^{\text {th }}$ day at different concentrations $(200,400,600 \mathrm{ppm})$ of sukh chain oil 


\section{Discussion}

In last few years, use of synthetic fungicides are the primary means of controlling post-harvest pathogens but have some limitations due to resistance to fungicides among fungal pathogens and high development cost of synthetic chemicals. Therefore, researchers has successfully introduced alternatives in the replacement of chemical fungicides especially plant derived products as disease control agents due to less toxic effects, ecofriendly and wide public acceptance (Seema et al., 2011). In few years, interest on plant EO has been increased for the control of post-harvest fungal pathogens due to environmental friendly nature. In this study, we examined the anti- microbial activities of some plant essential oils (Kikar, Moringa and Sukh chain) against Alternaria alternata causing fungal fruit rot and demonstrated that Sukh chain EO among all tested plants at different concentrations had considerable effect on the growth rate and spore germination respectively. Similar findings were also reported by Das et al. (2016) revealed that Pongamia pinnata (Sukh chain) essential oils exhibited its maximum zone of inhibition $(12.98 \mathrm{~mm})$ against $A$. alternata due to presence of some chemical compounds which are anti-fungal in nature viz. saponin, phenolic, triterpenes and flavonoid respectively. Our findings regarding mycelial growth inhibition are related with results demonstrated by Tripathi et al. (2013). According to their results, concentrations of plant essential oils are directly effect on fungal growth of pathogens. Higher concentrations of essential oils can inhibit maximum fungal growth. Recently, some studies have been conducted by several scientists on determination of anti-fungal activity of plant essential oils against fungal pathogens including Alternaria alternata (Satish et al., 2007; Jamil et al., 2007; Anwar and Rashid, 2007). The mechanism of plant essential oils involve, inhibition of hyphal growth, interruption in nutrient uptake, disruption of mitochondrial structure and eventually disorganization of fungal pathogens discussed by (Patel and Jasrai, 2011). Numerous plant essential oils like $P$. pinnata (Sukh chain), Vachellia nilotica, Thymus vulgare and Moringa oleifera have been found to be effective fungitoxic agents against several plant fungal pathogens reported by (Siripornvisal and Ngamchawee, 2010). Our result are in agreement with the findings of Feng and
Zheng, (2007) who used cassia oil at 500ppm concentration for controlling the germ tube length of Alternaria alternata, The findings in this study confirmed that Sukh chain essential oil might be used as natural fungicides.

\section{Conclusion}

The results obtained in the current study illustrated that Sukh chain oil has anti-fungal activity against Alternaria alternata under in vitro conditions. So, being less harmful and cheaper remedy, it can be used for controlling the A. alternata under field conditions.

Disclaimer: None.

Conflict of Interest: None.

Source of Funding: None.

\section{References}

Ali K, Maltese F, Choi YH and Verpoorte R, 2010. Metabolic constituents of grapevine and grapederived products. Phytochem. Rev. 9(3): 357378.

Anwar F and Rashid U, 2007. Physico-chemical characteristics of Moringa Oleifera seeds and seed oil from a wild provenance of Pakistan. Pak. J. Bot. 39(5): 1443-1453.

Arroyo FT, Moreno J, Daza P, Boianova L and Romero F, 2007. Antifungal activity of strawberry fruit volatile compounds against Colletotrichum acutatum. J. Agric. Food Chem. 55: 5701-5707.

Daferera DJ, Ziogas BN and Polissiou MG, 2003. The effectiveness of plant essential oils on the growth of Botrytis cinerea, Fusarium sp. and Clavibacter michiganensis subsp. michiganensis. Crop Prot. 22(1): 39-44.

Das SK, Roy A and Barman H, 2016. Fungi toxic efficiency of some plant volatile essential oils against plant pathogenic fungi. Afr. J. Microbiol. Res. 10(37): 1581-1585.

Dauria F, Tecca M, Strippoli V, Salvatore G, Battinelli L and Mazzanti G, 2005. Antifungal activity of Lavandula angustifolia essential oil against Candida albicans yeast and mycelial form. Med. Mycol. J. 43(5): 391-396.

Feng W and Zheng X, 2007. Essential oils to control Alternaria alternata in vitro and in vivo. Food Cont. 18(9): 1126-1130. 
Ghuffar S, Irshad G, Aslam MF, Naz F, Mehmood N, Hamzah AM, Mehmood A, Zeshan MA, Rehman S and Gleason ML, 2018a. First report of Mucor fragilis causing bunch rot of grapes in Punjab, Pakistan. Plant Dis. 102 (09): 1858.

Ghuffar S, Irshad G, Naz F, Rosli HB, Hyder S, Mehmood N, Zeshan MA, Raza MM, Mayer CG and Gleason ML, 2018b. First report of two Penicillium spp. causing post-harvest fruit rot of grapes in Pakistan. Plant Dis. 102(5): 1037.

Ghuffar S, Irshad G, Shahid M, Naz F, Riaz A, Khan MA, Mehmood N, Sattar A, Asadullah HM and Gleason ML, 2018c. First report of Alternaria alternata causing fruit rot of grapes in Pakistan. Plant Dis. 102(08): 1659.

Jamil A, Shahid M, Khan MM and Ashraf M, 2007. Screening of some medicinal plants for isolation of antifungal proteins and peptides. Pak. J. Bot. 39(1): 211-221.

Javed S, Javaid A, Anwar W, Majeed R, Akhtar R and Naqvi S, 2017. First report of Botrytis bunch rot of grapes caused by Botrytis cinerea in Pakistan. Plant Dis. 101(6): 1036.

Logrieco A, Moretti A and Solfrizzo M, 2009. Alternaria toxins and plant diseases: an overview of origin, occurrence and risks. World Mycotoxin J. 2(2): 129- 140.

Patel RM and Jasrai YT, 2011. Evaluation of Fungitoxic Potency of Medicinal Plants Volatile Oils (VOs) against Plant Pathogenic Fungi. Pesticide Res. J. 23(2):168-171.

Rathi P and Rajput CS, 2014. Antioxidant potential of grapes (Vitis Vinifera): A review. J. Drug Deliv. Sci. Technol. 4(2): 102-104.

Sahin F, Karaman I, Gulluce M, Ogutcu H, Sengul M, Adiguzel A and Kotan R, 2003. Evaluation of antimicrobial activities of Satureja hortensis L. J. Ethnopharmacol. 87(1): 61-65.

Satish S, Mohana DC, Raghavendra MP and Raveesha KA, 2007. Antifungal activity of some plant extracts against important seed borne pathogens of Aspergillus sp. J. Technol. 3: 109-119.

Seema MSS, Sreenivas ND and Devaki NS, 2011. In vitro studies of some plant extracts against Rhizoctonia solani Kuhn infecting FCV tobacco in Karnataka Light Soil, Karnataka,
India. J. Agric. Sci. Technol. 7(5): 1321-1329.

Siripornvisal S and Ngamchawee K, 2010. Utilization of herbal essential oils as biofumigant against fungal decay of tomato during storage. Proceedings16th Asian Agricultural Symposium, Bangkok, Thailand. pp. 655-658.

Tripathi P, Yami H and Shukla A, 2013. Impact of Essential Oils on Growth of Phytopathogenic Fungi Responsible for Rotting of Fruits. J. Adv. Biol. Biotechnol. 10(2): 1-10.

Tzortzakis NG, 2007. Maintaining postharvest quality of fresh produce with volatile compounds. Innov. Food Sci. Emerg. Technol. 8: 111-116.

Valero D, Valverde J, Martínez RD, Guillén F, Castillo S and Serrano M, 2006. The combination of modified atmosphere packaging with eugenol or thymol to maintain quality, safety and functional properties of table grapes. Postharvest Biol. Technol. 41(3): 317-327.

Wang CY, Wang SY, Yin JJ, Parry J and Yu LL, 2007. Enhancing Antioxidant, Antiproliferation, and free radical scavenging activities in strawberries with essential oils. J. Agric. Food Chem. 55: 6527-6532.

\section{Contribution of Authors}

Sajid A: Performed the experiments and manuscript write up

Irshad G: Planned and designed research experiments

Naz F: Planned and designed research experiments

Ghuffar S: Planned and designed research experiments

Hassan I: Planned and designed research experiments

Mahmood N: Data collection and analysis

Rani K: Data collection and analysis

Manzoor MF: Article write up and final approval Meesam A: Article write up and final approval Hamzah AM: Article write up and final approval Karamt MZ: Performed the experiments 